\title{
Performance e deficiência: caminhos para reinvenção da saúde
}

\author{
Performance and disability: ways to health reinvention
}

Tatiana Vasconcelos Santos (https://orcid.org/0000-0002-1547-0561) ${ }^{1}$

Martha Cristina Nunes Moreira (https://orcid.org/0000-0002-7199-3797) ${ }^{1}$

Romeu Gomes (https://orcid.org/0000-0003-3100-8091) ${ }^{1}$

${ }^{1}$ Instituto Nacional de Saúde da Mulher, da Criança e do Adolescente Fernandes Figueira, Fundação Oswaldo Cruz. Av. Rui Barbosa 716, Flamengo. 22250-020 Rio de Janeiro RJ Brasil. tatiufff@hotmail.com

\begin{abstract}
This essay aims to make a dialogue between disability studies in its postmodern aspect, with the Anthropology of Performance from two paths: 1) discussing bodily influence on the meanings attributed to the experience of disability; 2) discussing how performance, with emphasis on sport, places the body in the light of sociability, generating a tension between new body norms and the reproduction of current models on disability and health. We conclude that the performance of people with disabilities can contribute to a review or reinvention of the concept of health from the construction of new identities and empowerment projects. Thus, disability is separated from the biological function/dysfunction and brings it closer to the human being's action capacity in the world by the sociability established in sport.
\end{abstract}

Key words Disability, Sports, Health
Resumo Este texto, sob a forma de ensaio, tem como objetivo fazer uma interlocução dos estudos da deficiência, em sua vertente pós moderna, com a Antropologia da Performance a partir de dois caminhos: 1) discutir a influência do corpo nos significados atribuídos à experiência de deficiência; 2) discutir como a performance, com destaque para o esporte, coloca o corpo à luz da sociabilidade, gerando uma tensão entre novas normas para o corpo e reprodução de modelos vigentes sobre a deficiência e a saúde. Conclui-se que a performance da pessoa com deficiência pode contribuir para uma revisão ou reinvenção do conceito de saúde, a partir da construção de novas identidades e projetos de empoderamento. Desatrela-se assim a deficiência da função/disfunção biológica e a aproxima da capacidade de ação do ser no mundo pela sociabilidade instaurada no esporte.

Palavras-chave Deficiência, Esportes, Saúde 


\section{Introdução}

Hegemonicamente na literatura do campo da saúde e educação, as referências sobre deficiência costumam estar vinculadas ao diálogo com necessidades especiais em saúde, condições crônicas de saúde e construção da identidade com o reconhecimento do protagonismo da pessoa com deficiência ${ }^{1}$.

As interpretações de Goffman ${ }^{2}$ nos estudos sobre estigma e desvio, contribuíram para as reflexões sobre o lugar das interações sociais na construção das identidades sociais. Ainda que não tenha se dedicado exclusivamente a refletir sobre a deficiência, o autor considerou que a informação social emitida pelo corpo com deficiência (disabled body) pode levar ao julgamento da pessoa como uma desacreditada. Essa concepção pode ser internalizada e uma identidade social de desviante pode ser assumida. O problema aqui não está na marca corporal em si, mas nos sistemas simbólicos a ele atribuídos, produzindo significados que conferem sentido às experiências e modelam a identidade da pessoa com deficiência ${ }^{2}$.

Para além desses estudos, já no diálogo com as humanidades, destacamos os Estudos sobre Deficiência (Disability Studies) inaugurados no Reino Unido nos anos de 1970. Fortemente influenciado pelo modelo social, esse campo disciplinar centrou a discussão na deficiência como um fenômeno social, uma identidade, não relacionada à lesão (impairment) no corpo ${ }^{3}$. Nesse contexto, a primeira geração dos teóricos do modelo social teve como objetivo chamar a atenção para as barreiras sociais que criam as desigualdades desviando-se do foco biomédico sobre o corpo com deficiência, mas ainda trabalhando com a binaridade lesão/deficiência, quase como um contraste necessário entre biológico/social, como encontrávamos no paralelo sexo/gênero.

Internamente ao campo dos Disability Studies temos a teoria feminista produzindo uma vertente crítica na discussão sobre deficiência que acionará as categorias de gênero e cuidado como necessárias para tensionar esse campo ${ }^{4}$. Em síntese, a autora aponta que a deficiência em similaridade à raça e gênero, é um sistema de representação que marca corpos como subordinados.

Ainda dentro dos estudos feministas sobre deficiência, já em uma linhagem Foucaultiana e de diálogo Queer, temos a teoria Crip ${ }^{5}$ que questiona a corponormatividade (able-bodiedness) como uma das facetas do capacitismo (ableism) que domina as interpretações sobre o corpo com defi- ciência ${ }^{6}$. Segundo Mello ${ }^{6}$ o capacitismo se concretiza nas atitudes preconceituosas, produtoras de hierarquizações entre os sujeitos, buscando adequar seus corpos a um ideal de beleza e capacidade funcional. Esse campo de estudos proporciona um entendimento cultural da deficiência, iluminando as situações de desigualdade e discriminação como determinantes para a opressão que as pessoas com deficiência experienciam.

Tanto os estudos feministas sobre deficiência como a Teoria Crip vão problematizar a deficiência levando-a para um diálogo crítico acionando o corpo com deficiência, buscando acentuar a corporalidade e referir a mesma em diálogo com outros marcadores sociais.

No presente artigo, reconhecendo esses antecedentes como marcos teóricos para diálogos relevantes, buscamos o argumento da experiência da deficiência como uma reconfiguração do corpo para chegar a uma performance exitosa. E isso porque nosso diálogo tem como pano de fundo a experiência de adolescentes com deficiência física na sociabilidade do esporte. As reflexões podem nos conduzir a importantes apontamentos para estudos futuros acerca das dificuldades de adolescer com deficiência. Uma tensão com as novas exigências vitais internas e externas características dessa fase de vida que preconiza um corpo ativo, pronto para a sociabilidade. A valorização do corpo belo e preparado para o desempenho reforça um ideal capacitista que pode ser acionado pelos adolescentes quando inseridos no esporte de uma forma legitimadora da norma do corpo capaz (able-bodied).

Acionamos a Antropologia da Performance como uma base teórica para dialogar com a perspectiva da saúde, mas na operação com a categoria de intersubjetividade. Consideramos que os corpos com deficiência chegam a performances exitosas não apenas a partir de resultados de experiências individuais, mas podem chegar a esse padrão por meio da experiência que se configura a partir da intersubjetividade. Em outras palavras, a partir do ser em relação com os demais seres.

Com base em Schechner ${ }^{7}$, podemos considerar que uma boa performance significa conseguir realizar algo dentro de um padrão que leva a ser bem sucedido ou à excelência. Segundo esse autor: "Performances afirmam identidades, curvam o tempo, remodelam e adornam corpos, contam histórias"7 (p.27).

Cabe ressaltar que a articulação de uma idéia de performance, no contexto da Antropologia da Performance, às representações do "bem-sucedi- 
do, de fazer algo próximo a um padrão" pode ser bem questionada e discutida quando articulamos performance a uma discussão sobre experiência, no recorte específico do corpo com deficiência discutido nos estudos feministas sobre deficiência. Nesse caso não há como pensar corpo, se não pensar em redes de interdependência, implodindo o mito da independência ${ }^{8}$ e não articular a representação de um ideal de superação para atingir padrões normativos como um possível reforço de um projeto capacitista.

A partir dessas considerações objetivamos explorar a interlocução e as tensões dos estudos sobre deficiência, em sua vertente pós moderna, com a Antropologia da Performance. Para isso, utilizamos o ensaio como desenho metodológico, aqui entendido como exercício crítico de procura, de caráter exploratório, acerca de um tema ou objeto de meditação, buscando uma nova forma de olhar o assunto?.

Cumpre a função de um ensaio crítico não temer enfrentar um diálogo entre os Estudos feministas da deficiência e a Antropologia da Performance. Nesse caso articulada pelo conceito de experiência do corpo com deficiência que não é acionado pela Antropologia da Performance. Assim, reside nesse ensaio o argumento de que esse contraste entre uma definição genérica de experiência, na conversa com a sociologia compreensiva, e sua especificação com a ancoragem da experiência no corpo com deficiência, pode se revelar instigante para o campo da saúde coletiva, na perspectiva de um olhar sobre os sujeitos que constroem seus corpos no esporte.

\section{A experiência do corpo com deficiência}

Retomamos aqui de forma estratégica o conceito de experiência, a fim de situá-lo em uma perspectiva teórica que dialoga e opera com outro conceito estratégico, o de intersubjetividade, ancorados na discussão sobre o corpo como construção social.

A Experiência, aqui utilizada como um termo fenomenológico denota algo subjetivamente significativo que através de um ato de reflexão é conscientemente apreendido e cognitivamente constituído $^{10}$. A experiência sempre ocorre no mundo da vida, esfera circunscrita pelos objetos, pessoas e eventos onde nossas ações são realizadas. Segundo Schutz ${ }^{11}$, cada indivíduo constrói o seu próprio mundo, entretanto essa construção não surge a partir do nada. $O$ indivíduo o constrói com base nas relações que estabelece com outros indivíduos. O mundo da vida é o mundo intersubjetivo que antecede a vida de cada um e toda interpretação acerca desse mundo baseia-se num estoque de experiências prévias. Assim, "o mundo não é um mundo privado de um único indivíduo, mas um mundo intersubjetivo [...] [No entanto] nós não agimos apenas no mundo, mas também sobre o mundo"10(p.85). Por isso o conceito de experiência não se confunde à vivência, da particularidade e da intimidade de um indivíduo restrito ao seu eu, e nem ao de percepção. Na base da experiência está a possibilidade da construção compartilhada, no diálogo intersubjetivo, apreendido pelo sujeito no mundo, e que incorpora bagagens culturais anteriores, o chamado estoque de experiência.

Segundo Schutz ${ }^{10}$ as reservas de experiência se referem à sedimentação dos saberes herdados pelo indivíduo, seja por meio de suas experiências próprias, seja por meio de seus educadores - ou seja, sejam eles de natureza prática ou teórica. Tais reservas se ancoram na tipicalidade da vida cotidiana, que se refere ao modo pelo qual as diversas experiências sociais se conformam com base num modelo anteriormente estabelecido. Esse modelo está dialogando com as estruturas de pertinência, que são as formas de controle estabelecidas pelos indivíduos para organizar e reger as diversas situações sociais.

Como nossas ações sociais no mundo da vida envolvem interações entre pessoas, o corpo torna-se central, mediando a nossa relação entre a identidade pessoal e social, sendo o lócus de ancoragem e diálogo com e das experiências. Mais que um objeto em que os sistemas simbólicos são inscritos, o corpo atua como nosso veículo para estar no mundo, nosso meio de comunicação ${ }^{12}$. Para Mauss ${ }^{13}$ o corpo tanto é a ferramenta original com que os humanos moldam o seu mundo, como é a substância original a partir da qual o mundo humano é moldado. Ao utilizar-se de técnicas corporais os sujeitos servem-se de seus corpos de forma a atender à tradição de determinado contexto.

As valorizações da experiência e da prática favoreceram a ascendência do corpo como referência nas ciências sociais. Evocar a experiência significa valorizar a subjetividade e as emoções como partes integrantes dos processos investigativos de pesquisa. Conforme aponta Rezende ${ }^{14}$ : "A corporeidade é um ato metodológico que busca contrapor uma concepção de experiência compreendida e dominada pelo discurso" (p.4).

Csordas ${ }^{15}$ data os primórdios dos anos 1970, e com força crescente o final dos anos 1980, como 
fase em que o corpo assumiu uma presença viva na cena antropológica, e no palco dos estudos culturais interdisciplinares. O paradigma da corporeidade (embodiment) trouxe o entendimento de que somos agentes sociais corporificados, não apenas temos um corpo, mas somos um corpo, construído a partir do processo de reflexividade. Corpo entendido como corporalidade, sensibilidade e objetividade.

Com a luz na experiência, o corpo como instrumento da intencionalidade e da intersubjetividade ganha espaço, um físico dotado de agência, influente na construção social e cultural. Corpo e cultura passam a ser estudados então, a partir de uma relação dialógica. $\mathrm{O}$ corpo como um lugar onde as estruturas da sociedade se inscrevem, um veículo através do qual a sociedade é construída e um circuito que conecta os indivíduos com a sociedade. Como coloca Rodrigues ${ }^{16}$ : "a sociedade só encontra existência nos corpos pulsantes dos seres humanos que a constituem: ela é vísceras, nervos, sentidos, neurônios..." (p.177).

No campo dos estudos sobre deficiência, a entrada de abordagens pós modernas e de críticas feministas nos anos 1990 e 2000 levantaram a bandeira da experiência do corpo com deficiência, inaugurando a segunda geração do modelo social ${ }^{3}$. Alguns novos eixos de discussões se abrem.

O primeiro relaciona-se ao cuidado. Temas como dependência e interdependência foram reivindicados na agenda sobre deficiência considerando a condição de pessoas com quadros graves que necessitam de auxílio para atividades de vida diária e participação social. A filósofa Eva Kittay $^{17}$, cuidadora de uma filha com deficiência, trouxe à tona a questão do cuidado para além da questão de gênero, colocando a dependência como própria da condição humana.

O outro eixo refere-se ao corpo com deficiência. Sem negligenciar a construção social da deficiência, as feministas defenderam a ampliação do seu conceito para também abarcar as condições crônicas de saúde, uma nova abordagem da lesão que incluiria não só as descrições médicas, mas também a experiência do corpo com deficiência em variadas circunstâncias, uma fenomenologia da lesão conforme preconiza Wendell ${ }^{18}$. Ao defender a teorização tanto da deficiência quanto da lesão no campo dos Disability Studies, Thomas ${ }^{19}$ propõe que a deficiência existe quando as limitações experienciadas pelas pessoas com lesões são impostas pelas barreiras do ambiente. Essas limitações, segundo a autora, trazem repercussões psicoemocionais que devem ser abordadas nos estudos sobre deficiência. Nesse âmbito, a lesão deve ser considerada não como causa da deficiência, mas como matéria prima que tem um papel central de moldar a forma e o grau em que a limitação acontece.

Essas pautas, até então, estavam negligenciadas pelo modelo social, pois se acreditava que, a partir da retirada das barreiras sociais, seria possível o desenvolvimento das capacidades produtivas da pessoa com deficiência. Pensava-se também que as narrativas sobre as experiências do corpo com deficiência deveriam permanecer em âmbito privado para não colocar foco na lesão e prejudicar as reivindicações de que a deficiência era social e não individual.

Ainda problematizando a questão do corpo com deficiência, temos mais recentemente, a teoria crip $^{5}$. Assim como a teoria queer que questiona as normas regulatórias que estabelecem a "heteronormatividade compulsória"20, a teoria crip, apoiada na vertente pós estruturalista, busca uma posição analítica crítica em relação à obrigatoriedade do corpo capaz e a materialidade do corpo com deficiência como inferior.

A crítica feminista e da nova geração de teóricos sobre a deficiência deve ser compreendida como um processo de expansão e revigoramento do modelo social ${ }^{3}$. Os argumentos demandaram um olhar para o corpo com deficiência como objeto da ação social, receptáculo da inscrição de símbolos culturais estigmatizantes, mas também como produtor de agência, local da experiência, veículo e motor de constituição de novos significados e da construção de si. Ao mesmo tempo destacaram a ideia da interdependência como base da experiência humana, ou seja, todos somos interdependentes, rompendo com a mística da independência como fratura entre os que têm e os que não têm deficiências.

Em consonância com esse argumento, $\mathrm{Hu}-$ ghes e Paterson ${ }^{21}$ propõem uma articulação para os estudos sobre deficiência, em que se valorizem perspectivas teóricas não dualistas que forneçam além de, uma discussão cultural e de processos sociais envolvidos na deficiência, uma abordagem fenomenológica para a compreensão da experiência a partir do corpo com deficiência.

\section{Articulando experiência e performance}

Uma compreensão da experiência de deficiência de forma corporificada pode ser possível através da Antropologia da Performance. Schechner e McNamara (1982 apud Ligiéro ${ }^{22}$, p.10) concei- 
tuam performance como "modo de comportamento, uma abordagem à experiência; é exercício lúdico, esporte, estética, entretenimentos populares, teatro experimental, e muito mais". É a expressão de significados através do corpo, ajudando pessoas a lidar com transições difíceis, relações ambivalentes que problematizam, excedem ou violam as normas da vida diária; os dramas sociais.

Na Antropologia da Performance, o paradigma do corpo e "embodiment" contribuem com uma discussão que visa entender a possibilidade de transformação fenomenológica no nível mais profundo do corpo, agregando os aspectos emocionais, racionais e corporais da experiência ${ }^{23}$.

Para o entendimento de como a Antropologia da Performance pode dialogar com a experiência de deficiência cabe aqui fazer uma breve descrição das fases do drama social descritos por Turner ${ }^{24}$ : 1 ruptura: ocorre uma situação que ameaça a estabilidade de uma unidade social (família, comunidade, nação); 2 crise e intensificação da crise: os sujeitos/atores atingidos atuam e acionam suas redes de apoio, a crise é uma expansão da ruptura que se tornou aberta ao público; 3 ação reparadora: ocorre a mobilização dos sujeitos/ atores envolvidos em busca de soluções e esforços de conciliação, é o momento de reflexividade. A força $a^{25}$ - impulso ou projeção - alcançada a partir de uma experiência limite impulsiona o individuo para a ação. Os estilos performáticos são nessa fase acionados pela sua capacidade de investigar as fraquezas de uma comunidade, retratar conflitos característicos e sugerir formas de reparação; 4 desfecho: os esforços da fase anterior, quando bem-sucedidos, implicam um rearranjo e redefinições de posições instaurando uma relação de harmonia. A cisão ocorre se a ação reparadora for mal sucedida.

Vitor Turner ${ }^{26}$, baseando-se em Dilthey, propõe uma articulação entre a Antropologia da Experiência e a Antropologia da Performance ao enunciar que "A experiência incita a expressão, ou a comunicação, com os outros. Somos seres sociais e queremos dizer o que aprendemos com a experiência" ${ }^{26}$ (p.180). A pintura, a dança, o esporte, são instrumentos de expressão de significados colocando-os em circulação, uma atitude proposicional, reflexiva e expressiva como nos aponta a fenomenologia.

As performances interrompem o fluxo do mundo da vida. Ao deslocar o olhar dos atores de seus papéis normativos, faz com que eles adotem uma atitude reflexiva em relação à estrutura social possibilitando a sua revitalização. Turner aponta que a estrutura social (realidade cotidiana) e a antiestrutura (momentos de dramas sociais) realizam uma interlocução. Em um determinado momento a estrutura institui a antiestrutura; em um segundo momento, a antiestrutura tende a contribuir para revitalização da própria estrutura social ${ }^{27}$. Entendendo que somos corpos para o mundo (toward the world) ligados a ele pela teia de fios intencionais que são emitidos por nós, o corpo participa do processo de revigoramento da estrutura social ${ }^{28}$.

Se pensarmos a deficiência como uma experiência que pode ser dramática a depender do contexto sócio cultural onde ocorre, a performance seria como uma ação reparadora de uma experiência de deficiência conflituosa. Para a construção biomédica dominante, o corpo com deficiência pode ser considerado uma aberração, imperfeito e anormal. Porém, a pessoa com deficiência pode utilizar o seu corpo como recurso que a permite explorar novas possibilidades e oportunidades. As limitações podem ser catalisadoras de novas formas de uso de si.

Cumpre esclarecer duas críticas que podem surgir a partir dessa linha argumentativa. A possibilidade de exploração de novas capacidades não deve ser aqui evocada como uma estratégia para alcance de independência, mas como um processo de construção de uma "autonomia intersubjetiva" 29 a depender das redes de relações sociais que a pessoa com deficiência estabelece. O outro ponto a ser esclarecido refere-se ao risco do argumento ser utilizado como um perpetuador de um estereótipo de manejo da deficiência relacionado às narrativas de superação de limites. Queremos, por outro lado, dar ênfase às repercussões internas de uma interação exitosa como, por exemplo, o empoderamento e a construção de identidade.

Com impedimentos, o corpo é experienciado de uma forma diferente, sendo necessário um re-embodiment criativo ${ }^{30}$. A condição de deficiência física, por exemplo, faz com que os atributos corporais transpareçam à consciência durante uma interação. Devido a uma maior assimilação da percepção do corpo, a forma é continuamente escrutinizada por um olhar diagnóstico, denunciando a pergunta não dita que interroga "o que houve com você?"31.

A pessoa com deficiência física precisa então negociar duas condições culturais: a invisibilidade como membro ativo na esfera pública e a hipervisibilidade que o corpo suscita. Através da performance é possível encontrar uma outra possibilidade para o "ocularcentrismo" questio- 
nador, criando imagens que convidam a contemplação visual, ampliando as possibilidades de símbolos, espaços e ocupações de seus corpos com lesão ${ }^{31}$.

Aqui cabe o diálogo com o componente da imagem corporal que representa o ponto de vista do Outro, o valor ${ }^{32}$. Representando a interiorização pelo sujeito do juízo social que cerca os atributos físicos que o caracterizam, o valor que a pessoa com deficiência atribui a sua imagem pode ser alterado através da performance graças ao seu potencial transformador do juízo negativo associado a lesão no corpo.

A experimentação de novas práticas corporais através da performance possibilita ressignificar a deficiência à partir da interação social. Apropriando-se do conceito de rituais de apagamento do corpo citado por Le Breton ${ }^{32}$ e extrapolando -o para a condição de deficiência física em que as características corporais estão em destaque, a performance poderia ser utilizada como um ritual de apagamento do corpo com deficiência física. Os atributos físicos deixam de ser o foco na interação, instaura-se um processo de desconstrução da incapacidade associada à deficiência ao se questionar as normas que materializam e naturalizam esses corpos. A normalidade do corpo capaz pode assim ser questionada.

Considerar a deficiência em seu aspecto corporal e como uma forma de expressão de capacidades através da interação é pensá-la como performance. Goffman ${ }^{33}$ faz referência ao termo como desempenho de papéis enquanto um tipo de comportamento ritual dos atores sociais na vida cotidiana. Voltando-se para o exame da experiência do ator por meio dos tipos performáticos, Turner ${ }^{26}$ utiliza o conceito de performance associado a experiências que foram formativas e transformativas, isto é, sequências distinguíveis de eventos externos e de reações internas a eles desencadeando iniciações em novos modos de vida. Desloca o olhar do teatro da vida cotidiana trazido por Goffman para o meta-teatro da vida social acreditando que "nas irrupções do extraordinário também se encontra a experiência do ordinário"34(p.174).

Expressões performáticas, como por exemplo, o esporte, contribui para a expressão de uma identidade muitas vezes dissociada daquela do mundo cotidiano. Para a pessoa com deficiência, performar o corpo de outras maneiras possibilita uma redefinição de si mesmo.

Queremos lançar luz sobre o potencial disruptivo do esporte como mecanismo de se criar novas normas para o corpo com deficiência. Po- rém, há também necessidade de se problematizar este espaço como reprodutor de normas hegemônicas relacionadas ao corpo capaz, mantendo a deficiência como marginal.

\section{O corpo com deficiência como potência}

Ao falarmos de corpo como potência acionamos os conceitos de Aristóteles ${ }^{35}$. Ao se ocupar do termo Ser em suas diversas acepções, o filósofo conceitua potência como a fonte de mudança em alguma outra coisa. O movimento é definido pelo filósofo como a realização do que está em potência. Assumimos o corpo com deficiência como uma potência, um princípio originador de mudanças que se expressa através de movimentos em diferentes estilos performáticos.

Considerando a performance como uma via de tornar ou explicitar a potência do corpo com deficiência e um espaço para exercício da intersubjetividade, queremos destacar o esporte como um dos caminhos possíveis para uma performance exitosa da pessoa com deficiência, uma via de quebra da associação mecânica entre deficiência e incapacidade.

Historicamente, o desenvolvimento do esporte foi associado ao seu auxílio na invenção, ensaio e consolidação de habilidades corporais que garantiam alimentação, abrigo e proteção física. Transcendendo seu papel inicial de provedor de necessidades materiais e físicas, os esportes assumiram um papel vital em estabelecer e manter as relações sociais e a identidade cultural de coletividade ${ }^{36}$. O esporte hoje provê uma visão de como a vida pode ser vivida quando não constantemente dominada pela necessidade. É um gerador de regras que extrapolam para nossas condutas no mundo da vida, é onde, a partir das interações, assumem-se traços identitários e ainda um local de expressão de sentimentos. Através do esporte, podemos forjar relações que podem espelhar, sustentar ou antecipar mudanças no próprio esporte e na vida social ${ }^{36}$.

O esporte é associado a ideais hegemônicos de masculinidade, fisicalidade e desenvolvimento de capacidades. Esse cenário estabelece-se como um espaço profícuo para problematização da reiteração social de uma superioridade do corpo capaz quando comparado ao corpo com deficiência ${ }^{37}$.

Questões de gênero estão envolvidas nesse processo por balizar valores associados à performance física. As expressões performáticas podem reproduzir, desafiar ou transcender a dicotomia 
masculino/feminino e os conceitos associados à normalidade e anormalidade ${ }^{31}$.

Para o homem com deficiência, a inserção no esporte e o desenvolvimento do corpo, promovem a autoestima e os sentimentos de potência e capacidade, oferecendo a ele uma oportunidade para reafirmar os seus valores de masculinidade. Por outro lado, o body building não se encaixa nas noções convencionais de feminilidade. A mulher é vista como uma atleta na cadeira de rodas e o gênero, neste caso, é erradicado. A categoria social de atleta e os significados associados à cadeira de rodas transcendem a feminilidade. Nesse sentido, a primazia da fisicalidade masculina reforçada pelo esporte auxilia de forma mais proeminente o suporte de identidade e o senso de pertencimento dos homens com deficiência em um contexto em que a normalidade corporal é tida como compulsória. A mulher com deficiência inserida no esporte deve fazer um exercício para reafirmação de sua identidade por outras vias tais como sentir-se atraente a partir de um corpo em forma ou estar bem fisicamente para exercer suas atividades de cuidado ${ }^{30}$.

Creditar o sucesso no esporte à habilidade de se atender as normas de um corpo capaz acaba por reforçar o que McRuer ${ }^{5}$ chama de corponormatividade compulsória (compulsory able -bodiedness), termo utilizado para descrever um entendimento cultural que coloca a compreensão da deficiência com base em um ideal de falta de imperfeição. É justamente a crítica a materialização dos corpos com deficiência como inferiores, buscando desconstruir o processo regulatório de normalização que permeia a divisão entre corpos que se baseia a teoria crip postulada pelo autor.

No esporte, o discurso de superação com vistas a se alcançar o desempenho próximo a corpos sem deficiência, reforça o capacitismo pressionando os sujeitos a agirem de forma a superar as limitações, extraordinários pela capacidade de triunfar apesar da deficiência ${ }^{37}$.

Queremos destacar o diálogo entre esporte e deficiência não apenas como uma forma de se alcançar uma representação convencional de corpo capaz reforçando um ideal de corponormatividade compulsória. Para além da noção de normalidade, a performance esportiva lança luz sobre a deficiência tendo como referência a normatividade de Canguilhem ${ }^{38,39}$. A concepção do autor de que o padrão de saúde do sujeito é caracterizado pela sua capacidade de criar novas normas, pode ser extrapolada para o campo da deficiência. A performance esportiva pode ser uma atividade criativa polarizada contra o que é decréscimo e impotência, produzindo novas normas de enquadramento do corpo com deficiência na sociedade.

Instaura-se uma forma de autonomia e sociabilidade em que o corpo assume a posição de agência, movimento e controle. Nesse caso o corpo com deficiência opera intersubjetivamente, exercitando a interdependência com a prática esportiva que desenvolve o corpo como potência, controle, reinvenção, reconhecimento de valores e virtudes. Aqui cabe fazer uma menção ao conceito de autonomia intersubjetiva e derivada do reconhecimento discutido por Honneth ${ }^{28}$ como forma de afastar a possibilidade de associação da autonomia à independência. Nesse contexto, a atenção se volta aos sentimentos de autoconfiança, autorrespeito e auto-estima derivados do reconhecimento nas relações sociais. No caso da performance no esporte, o reconhecimento auxilia na autorrealização social da pessoa com deficiência.

O esporte constrói uma interlocução entre as pessoas com e sem deficiência e também oferece uma crítica aos limites aparentes do corpo ${ }^{31}$. A hexis corporal envolvida no esporte compõe um sistema de símbolos que promovem um novo lugar ao físico e uma reformulação da identidade. A forma considerada com desvio se dissolve no exercício da atividade esportiva. Ameniza-se, assim, o sentimento de estar mantido à distância devido a seus atributos físicos, reinserindo-se no campo simbólico que dá sentido e valor às ações sociais.

Como catalisador de emoções, o esporte oferece oportunidades de experienciar satisfações emocionais associadas ao exercício das capacidades físicas ${ }^{40}$. Através de uma criação de tensões, os sentimentos são animados. Perigo imaginário, medo, entusiasmo, tristeza e alegria são produzidos e possivelmente resolvidos no quadro dos divertimentos. Estados contrastantes são dinamizados, como a angústia e a exaltação, a agitação e a paz de espírito.

A interação que ocorre na performance esportiva autoriza a manifestação coletiva de sentimentos intensos, é o esporte como o suporte do que Simmel ${ }^{41}$ chamou de sociabilidade. Processos puros de associação com fins neles mesmos, que forjam um mundo artificial construído por seres que desejam produzir uma interação pura não desequilibrada por nenhuma tensão material.

Turner descreve a experiência de communitas como um sentimento de solidariedade de grupo, gerada durante um ritual e que pode acontecer durante o esporte em que ao jogar muito bem, 
cada jogador se sente em contato íntimo com os outros, um senso de "nós estamos todos juntos"22.

Em contraste ao ambiente muitas vezes hostil e discriminatório do mundo da vida, o grupo onde a performance ocorre pode ser considerado como local de pertencimento e compartilhamento de interesses comuns, um lugar de sociabilidade protegid $a^{42}$. O significado subjetivo do grupo decorre do compartilhamento de tipificações e relevâncias definindo papéis sociais, posições e o status de cada um. A utilização de um sistema comum de relevâncias leva a uma autotipificação homogênea pelos membros do grupo permitindo que seja construído um espaço de acolhimento e reconhecimento onde novas normas podem ser elaboradas.

\section{Considerações Finais}

$\mathrm{Na}$ interface do corpo com deficiência e a performance, a saúde em geral deve ser revista ou até mesmo reinventada. A começar pela desconstrução de certas associações mecânicas sem serem problematizadas, como lesão-doença e deficiência-incapacidade. Um corpo com deficiência pode, em determinadas situações e condições, ter uma performance voltada para fins específicos com melhor êxito do que o corpo sem deficiência. Por outro lado, a deficiência nem sempre é impedimento da funcionalidade. Isso pode ser equacionado quando nos libertamos de idealizações ou padrões únicos para chegarmos à concepção de deficiência que comporte uma diversidade de estilos de vida e compreendendo-a como um valor moral positivo.

O foco na capacidade de ação do sujeito no mundo da vida através de estilos performáticos contribui para superação da perspectiva naturalista em saúde em que corpos com deficiência são relatados como taxas de incidência e desvios da norma estatística. Esses dados são importantes como pontos de partida para se pensar projetos de inclusão ou assistência aos adolescentes com deficiência, mas nunca como um ponto de chegada para compor um simples perfil ou um relatório de como se configura a relação de corpos com deficiência e sem deficiência.

Outro aspecto importante de salientar no diálogo entre performance e a saúde em geral é o afastamento da ideia de normalização, em que o ato performático exitoso atuaria como um simples caminho para a aceitação e superação dos corpos com deficiência ou até mesmo para que se consiga apresentações públicas unicamente com fins de entretimento ou até mesmo lucrativos. Associado a isso, faz-se necessário que a performance não seja reduzida a um produto do capacitismo para que se obtenha a aceitação social dos corpos com deficiência. Nesse sentido, as superposições performance/esporte/saúde/ educação devem ser complexificadas. Para adolescentes com deficiência, as experiências em um contexto de corponormatividade compulsória podem fazer com que o viés capacitista do esporte seja acionado de uma forma não crítica, colonizando-os em um padrão que os restringe não possibilitando a afirmação da deficiência.

Queremos lançar luz sobre a performance a ser conseguida por esses corpos como um reflexo de dimensões internas, como projetos de empoderamentos, construções de identidade pessoal, vivência de prazeres, estabelecimento de vida societária, dentre outras.

Por fim, assinalamos que a discussão levantada por nós ainda é atravessada de incertezas, desafios e impotências. Porém, se pelo menos esses aspectos causarem um certo incômodo ou desconforto frente ao tema, poderemos, como profissionais de saúde, não só repensarmos ações que deem continuidade à discussão, mas nos reinventarmos para olhar outros horizontes. 


\section{Colaboradores}

TV Santos foi responsável pela concepção, delineamento e redação do artigo. MCN Moreira e R Gomes participaram na concepção, delineamento e revisão crítica.

\section{Referências}

1. Santos TV, Moreira MCN, Gomes R. When participation of children and youth with disabilities is not merely activity: a study of the literature. Cien Saude Colet 2016; 21(10):3111-3120.

2. Goffman E. Estigma. Rio de Janeiro: Guanabara Koogan; 1988.

3. Diniz D. O que é deficiência. São Paulo: Editora Brasiliense; 2012.

4. Garland-Thomson R. Feminist Disability Studies. Signs 2005; 30(2):1557-1587.

5. McRuer R. Crip Theory: Cultural Signs of Queerness \& Disability. New York: New York University Press; 2006.

6. Mello AG. Deficiência, incapacidade e vulnerabilidade: do capacitismo ou a preeminência capacitista e biomédica do Comitê de Ética em Pesquisa da UFSC. Cien Saude Colet 2016; 21(10):3265-3276.

7. Schechner R. O que é performance. O Percevejo 2003; 12: 25-50.

8. Butler J. Yo quiero ser más débil [Internet]. [acessado 2018 Out 01]. Disponível em: https://www.elsaltodiario.com/gsnotaftershave/judith-butler-yo-quiero-ser -mas-debil

9. Tobar F, Yalour MR. Como fazer teses em saúde pública: conselhos e ideias para formular projetos e redigir teses e informes de pesquisas. Rio de Janeiro: Fiocruz; 2002.

10. Schutz A. Sobre a fenomenologia e relações sociais. Petrópolis:Vozes; 2012.

11. Schutz A. El problema de la realidade social. Buenos Aires: Amorrurtu; 2008.

12. Merleau-Ponty M. Fenomenologia da percepção. São Paulo: Editora WMF Martins Fontes; 2011.

13. Mauss M. Sociologia e Antropologia. São Paulo: Ubu Editora; 2017.

14. Rezende MVB. Corpo, experiência e performance: perspectivas teórico-metodológicas anti-conceituais. Artefactum Rev Est Ling Tecnol 2015; 2:1-12.

15. Csordas TJ. Embodiment as a paradigm for anthropology. Ethos 1990;18(1):5-47.

16. Rodrigues JC. O corpo na história. Rio de Janeiro: Editora Fiocruz; 1999.

17. Kittay EF. Love's Labor: essays on women, equality and dependency. New York: Routledge; 1999.

18. Wendell S. Unhealthy disabled: treating chronic illnesses as disabilities. Hypatia 2001; 16(4):17-33.

19. Thomas C. How is disability understood? An examination of sociological approaches. Disabil Soc 2004; 19(6):569-583.

20. Rich A. Compulsory Heterosexuality and Lesbian Existence. Signs 1980; 5(4):631-660.

21. Hughes B, Paterson K. The social model of disability and the disappearing body: towards a sociology of impairment. Disabil Soc 1997; 12(3):325-340.

22. Ligiéro Z, organizador. Performance e Antropologia de Richard Schechner. Rio de Janeiro: Mauad X; 2012.

23. Langdon EJ. Performance e sua diversidade como paradigma analítico: a contribuição da abordagem de Bauman e Briggs. In: Programa de Pós Graduação em Antropologia social, Universidade Federal de Santa Catarina. Antropologia em primeira mão. Florianópolis: UFSC; 2007. p. 5-26.

24. Turner V. Do ritual ao teatro. Rio de Janeiro: Editora UFRJ; 2015. 
25. Dilthey W. Introduction a las ciencias del espiritu. Madri: Revista de Occidente; 1956.

26. Turner V. Dewey, Dilthey e Drama: um ensaio em Antropologia da Experiência (primeira parte) de Victor Turner. Cad Campo 2005; 13:177-185.

27. Silva RA. Entre "artes" e "ciências": a noção de performance e drama no campo das ciências sociais. Horiz Antropol 2005; 11(24):35-65.

28. Csordas TJ. Fenomenologia cultural corporeidade: agência, diferença sexual, e doença. Educação 2013; 36(3):292-305.

29. Honneth A. Luta por reconhecimento. São Paulo: Editora 34; 2009.

30. Seymour W. Remaking the body. New York: Routledge; 1998.

31. Sandahl C, Auslander P, organizadores. Bodies in commotion: disability and performance. Ann Arbor: The University of Michigan Press; 2005.

32. Le Breton D. Antropologia do corpo. Petrópolis: Vozes; 2016.

33. Goffman E. Ritual de interação: ensaios sobre o comportamento face a face. Petrópolis: Vozes; 2012.

34. Dawsey JC. Victor Turner e a Antropologia da Experiência. Cad Campo 2005; 13:163-176.

35. Aristóteles. Metafísica. São Paulo: Edipro; 2012.

36. Shilling C. The body in culture, technology and society. London: Sage publications; 2005.

37. Silva CF, Howe PD. The (In) validity of supercrip representation of Paralympian Athletes. J Sport Soc Issues 2012; 11(2):174-194.

38. Canguilhem G. O normal e o patológico. Rio de Janeiro: Forense Universitária; 2015.

39. Gaudenzi P, Ortega F. Problematizando o conceito de deficiência a partir das noções de autonomia e normalidade. Cien Saude Colet 2016; 21(10):3061-3070.

40. Elias N, Dunning E. A busca da excitação. Lisboa: Difel; 1992.

41. Simmel G. Questões fundamentais da sociologia. Rio de Janeiro: Zahar; 2006.

42. Wacquant L. Corpo e alma: notas etnográficas de um aprendiz de boxe. Rio de Janeiro: Relume Dumará; 2002.

Artigo apresentado em 05/10/2018

Aprovado em 21/11/2018

Versão final apresentada em 23/11/2018 